\title{
Gestão do Projeto Político-Pedagógico do Curso de Ciências Contábeis e o Currículo como Instrumento de sua Concretização
}

\author{
Knowledge Management at the University: The Political Educational Project \\ for the Accounting Sciences Course and the Curriculum as Instruments of its \\ Establishment
}

Isac Pimentel Guimarães

Mestrando em Educação (UFBA)

\author{
Vilma Geni Slomski \\ Ph.D em Contabilidade e Controladoria (USP) \\ Doutora em Educação (USP) \\ Mestre em Educação (USP) \\ Professora da FECAP/SP
}

\author{
Sônia Maria da Silva Gomes \\ Doutora em Engenharia da Produção (UFSC) \\ Mestre em Contabilidade e Controladoria (USP) \\ Professora Titular do Departamento de \\ Contabilidade (UFBA) \\ Professora do Programa do Mestrado em \\ Contabilidade (UFBA)
}

\section{Resumo}

Novo modelo de ciência e novas tendências epistemológicas emergem determinando outras formas de conceber e representar a realidade atingindo, deste modo, diferentes áreas do conhecimento, perpassando também o discurso e as práticas pedagógicas que constroem e constituem o cotidiano da Universidade. Este artigo tem como objetivo refletir sobre formas de gestão do conhecimento na universidade, procurando identificar e apontar os processos que orientam a construção coletiva do Projeto Político Pedagógico do curso de Ciências Contábeis tendo o currículo como seu instrumento de concretização. Para tanto, desenvolveu-se um ensaio teórico, onde foram discutidos estudos e pesquisas que analisam criticamente o atual modelo de universidade e sua organização curricular conseqüente (MAZETTO, 2003; PIMENTA, 2002; LIBÂNEO, 2001; CUNHA, 2001), como contraponto apresentou-se e discutiram-se estudos que defendem a construção coletiva do Projeto Político Pedagógico do curso, a prática pedagógica reflexiva e a estruturação de currículos interdisciplinares (DIAS, 2005; CHAUÍ, 1999; MORAES, 1996; CUNHA, 1998; SANTOS 2006; MORIN, 2005; FAZENDA, 2002; MAZETTO, 2003; LIBÂNEO, 2001; PIMENTA, 2002). Constatou-se que a gestão participativa da IES exige visão integrada do conhecimento e postura interdisciplinar. Estes princípios epistemológicos revelam-se no contexto do ensino universitário pela construção coletiva do PPP, pela organização de currículos globalizados e por práticas pedagógicas coletivas, como comuns e esclarecedoras da própria vivência docente. Concluise, assim, que a gestão democrática exige a relação dialógica dos envolvidos e o uso de técnicas e habilidades humanas eficazes e adequadas aos objetivos a que se propõe a Educação Superior, em especial os cursos de graduação.

Palavras chave: Gestão do conhecimento. Projeto Político Pedagógico. Curso de Contabilidade. Currículo globalizado.

\section{Abstract}

A new science model and novel epistemological trends appear and determine other ways of conceiving and representing reality; this way, they reach new fields of knowledge, intertwining the pedagogical discourse and practices that build and constitute the everyday life of the University. This article aims at reflecting on the ways knowledge is managed at the University, and tries to identify and point out the processes that guide the collective construction of the Political and Educational Project of the Accounting Sciences course, 
having the curriculum as its instrument of establishment. To do so, a theoretical essay was developed containing the discussion of studies and research that critically analyze the current university model and its consequent curricular organization (MAZETTO, 2003; PIMENTA, 2002; LIBÂNEO, 2001; CUNHA, 2001). The counterpoint is the presentation and discussion of studies that defend the collective construction of the Political and Educational Project of the course; the reflexive pedagogical practice; and the structuring of interdisciplinary curricula (DIAS, 2005; CHAUÍ, 1999; MORAES, 1996; CUNHA, 1998; SANTOS 2006; MORIN, 2005; FAZENDA, 2002; MAZETTO, 2003; LIBÂNEO, 2001; PIMENTA, 2002). It became evident that participative management of IES (higher education institutions) requires an integrated view of knowledge, and interdisciplinary attitude. These epistemological principles become visible in the context of university education by means of the collective construction of the PPP; the organization of globalized curricula; as well as collective pedagogical practices, common to and enlightening the very teaching experience. The conclusion reached is that democratic management requires not only a dialogic relationship among the ones involved, but also the use of techniques and human abilities efficient and adequate to the objectives pursued by Higher Education, especially under graduation courses.

Keywords: Knowledge Management; Political Educational Project; Accounting Course; Globalized Curriculum.

\section{INTRODUÇÃO}

As formas tradicionais de conceber o conhecimento vêm revigorando a discussão sobre currículo e métodos de ensino/aprendizagem, trazendo novas exigências ao debate pedagógico na Universidade. Hargreaves (2004) numa análise sobre a contemporaneidade diz que a sociedade do conhecimento é uma sociedade de aprendizagem. Este imperativo impõe mudanças na relação homem x conhecimento tendo em vista novas formas de conceber e de pensar a realidade.

Isto remete aos estudos de Santos (2006) que identifica o contexto social contemporâneo como um tempo de transição paradigmática entre o moderno (paradigma dominante) e o pós-moderno (paradigma emergente). Como implicações desta transição, têmse de um lado as certezas e verdades incontestáveis, o conhecimento passível de mensuração e previsibilidade, o dualismo de idéias (certo/errado; bem/mal..); por outro as dúvidas e incertezas, imprevisibilidade e complexidade. Análise semelhante do contexto atual encontrase no trabalho de Roza (2005, p.45) que escreve: "este se configura como uma nova percepção de mundo, de homem, de ciência. As verdades absolutas dão lugar ao reino das incertezas; o conhecimento lógico e definido cede lugar ao conhecimento provisório".

Esta realidade perpassa diferentes áreas do saber e atinge também os discursos e as práticas pedagógicas que constroem e que constituem o cotidiano da Universidade. Diferentes pesquisas apontam para a necessidade de mudanças curriculares (SAVIANI, 2000, MORAES, 1996, CUNHA, 1998; SANTOS, 2006; MORAN, 2001, 2005; FAZENDA, 2002), estes trabalhos ressaltam que "o problema da educação decorre do modelo da ciência que prevalece num certo momento histórico e que influencia as questões epistemológicas e as teorias de aprendizagem das quais derivam a mediação pedagógica e suas práticas correspondentes" (MORAES, 1996, p.3).

A visão dominante de ciência é regida por um rigoroso determinismo, privilegia o "como fazer" em detrimento do "por que fazer". Tal fato conduz à fragmentação e à especialização, e, deste modo, ao surgimento de metodologias de ensino que não permitem conflitos cognitivos, percebidos como essenciais às atividades de aprendizagem. Chaves (2007, p. 30) assevera que "os grandes desafios humanísticos, científicos e tecnológicos têm quase sempre caráter interdisciplinar e somente podem ser resolvidos por equipes de 
profissionais de diversas áreas". Isto significa dizer que para garantir sua empregabilidade, o profissional precisa alargar sua visão de mundo, sem se isolar em especializações que, embora lhe permitam exercer a profissão, negam-lhe a competência exigida pelo mundo do trabalho global.

Edgar Morin, teórico da complexidade e da interdisciplinaridade, entende que só o pensamento sistêmico sobre uma realidade também complexa faz avançar a reforma do pensamento na direção da contextualização, da articulação e da interdisciplinarização do conhecimento gerado pela humanidade. Para o autor:

[...] a reforma necessária do pensamento é aquela que gera um pensamento do contexto e do complexo. O pensamento contextual busca sempre a relação de inseparabilidade e as inter-retroações entre qualquer fenômeno e seu contexto, e deste com o contexto planetário. $\mathrm{O}$ complexo requer um pensamento que capte relações, inter-relações, implicações mútuas, fenômenos multidimensionais, realidades que são simultaneamente solidárias e conflitivas (como a própria democracia, que é o sistema que se nutre de antagonismos e que, simultaneamente, os regula), que respeite a diversidade, ao mesmo tempo que a unidade, um pensamento organizador que conceba a relação recíproca entre todas as partes (MORAN, 2005, p. 23).

Esta mudança paradigmática na forma de conceber o homem e sua relação com o conhecimento têm estimulado reflexões sobre o papel social da universidade neste novo século. Sua função não é apenas capacitar os acadêmicos para novos postos de trabalho, mas principalmente para exercerem com consciência a cidadania, para o que a autonomia, o senso crítico e o desenvolvimento intelectual são pontos chaves no processo de inserção social e profissional. Este entendimento corrobora com a idéia de que a universidade deve zelar pela qualidade do trabalho acadêmico que realiza e pela competência dos profissionais que forma. Assim, deve priorizar o desenvolvimento de competências, habilidades, valores e conhecimentos em função dos novos saberes que se produzem e que exigem um novo perfil profissional.

Quando se questiona o desempenho do profissional formado pela Universidade é a qualidade do ensino ministrado que concretamente está sendo objeto de avaliação. Este dado remete à reflexão sobre o papel do docente, sobre a prática do ensino universitário e sobre a construção de um Projeto Pedagógico que concretize os objetivos da Universidade como instituição produtora do conhecimento científico e formadora de profissionais competentes a serviço da difusão do conhecimento e do desenvolvimento social (LDB, 1996).

Assim caminha a reforma universitária que instituída pela nova LDB (1996) que traz orientações governamentais para direcionar o processo de formação humana. A nova Lei em seu capítulo IV, Art. 43․ I., diz que a finalidade da educação é "estimular a criação cultural e o desenvolvimento do espírito científico e do pensamento reflexivo". Entretanto, o desenvolvimento do pensamento complexo e do pensamento reflexivo exige a superação do currículo tecnicista proposto para a transmissão de conteúdos e desenvolvimento de habilidades a serviço do sistema de produção. A visão unitária e mecanicista do conhecimento no ensino superior produz a realidade histórica dos currículos por disciplinas e o isolamento do corpo docente. Tem sido comum os docentes se enclausurarem em seus laboratórios, em seus problemas de pesquisa, em suas disciplinas com conteúdos descontextulizados ahistóricos e pouco ligados à prática social dos alunos.

Para sintonizar a universidade aos paradigmas do mundo moderno e à formação científica e tecnológica dos alunos, a LDB (1996), instituiu a adequação dos cursos de graduação via as Diretrizes Curriculares Nacionais - DCN, que superam os estreitos contornos de currículos mínimos obrigatórios, permitindo uma organização curricular com relativa liberdade e flexibilidade. Esta autonomia acadêmica e flexibilização curricular deve 
acontecer a partir da construção do Projeto Político pedagógico da IES, o qual poderá se tornar realidade por meio de um currículo interdisciplinar.

O PPP apresenta-se como o instrumento balizador do fazer universitário e, por conseqüência, expressa a prática pedagógica das instituições e dos cursos dando direção à gestão e às atividades educacionais, nesta direção, apresenta-se como um guia para a ação, que dá uma direção política e pedagógica para o trabalho docente acadêmico.Por meio dele se formula metas, se institui procedimentos e instrumentos de ação. A gestão põe em prática o processo organizacional para atender ao projeto de modo que este seja um instrumento de gestão.

Diante disto, o papel do coordenador do curso é de monitoração sistemática da prática pedagógica dos professores, sobretudo mediante procedimentos de reflexão e investigação. Estas preocupações foram contempladas pela LDB (1996), que imprime ao curso de graduação a forma de uma unidade acadêmico-administrativa dentro da IES e ao coordenador do curso o papel de gestor desta unidade. Esta gerência e administração do curso é entendida por Cantídio (1981) como a gestão de um projeto de aprendizagem. Isto significa dizer que o projeto pedagógico é um instrumento de construção da qualidade educação superior.Porém, ele precisa ser pensado e utilizado pelo seu gestor principal - o Coordenador do Curso.Todavia, percebe-se que, embora muito se tenha avançado em relação à discussão e elaboração coletiva dos projetos pedagógicos dos cursos, ainda podem ser identificadas algumas dificuldades em sua implementação e utilização.

Uma das questões que podem estar dificultando este processo refere-se ao fato de que esta função de gerência do ensino é atribuída a um professor, que por mais qualificado que seja em seu âmbito específico, ainda lhe faltam conhecimentos referentes ao processo educacional e pedagógico. São saberes referentes às questões didáticas ligadas ao processo de aprender e ensinar e, principlamente no nível universitário. Diante desta problemática teve-se como preocupação investigar que processos orientam a construção coletiva do Projeto Político Pedagógico do curso de Ciências Contábeis tendo o currículo globalizado como seu instrumento de concretização? Em busca de respostas e este questionamento o presente trabalho tem como objetivo refletir sobre formas de gestão do conhecimento na universidade, procurando identificar e apontar os processos que orientam a construção coletiva do Projeto Político Pedagógico do curso de Ciências Contábeis tendo o currículo globalizado como seu instrumento de concretização.

Para o alcance desta meta desenvolveu-se um ensaio teórico o qual consiste na exposição lógico-reflexiva com ênfase na argumentação e interpretação pessoal. Tomou-se como ponto de partida pesquisas e trabalhos científicos analisam criticamente o atual modelo de universidade e de sua organização curricular conseqüente (DIAS, 2005; CHAUÍ, 1999; MORAES, 1996; CUNHA, 1998; SANTOS 2006; MORIN, 2005; FAZENDA, 2002; MAZETTO, 2003; LIBÂNEO, 2001; PIMENTA E ANASTASIOU, 2002) e, dentre estes, analisou-se e discutiu-se contribuições que defendem a gestão democrática da IES, a relação dialógica e o uso de técnicas e habilidades humanas eficazes e adequadas aos objetivos a que se propõe a Educação Superior, em especial os cursos de graduação (MAZETTO, 2003; PIMENTA e ANASTASIOU, 2002; LIBÂNEO, 2001; CUNHA , 1998, 2001). Estes trabalhos defendem a construção coletiva do Projeto Pedagógico do curso e a estruturação de currículos interdisciplinares, com vista a integração das disciplinas, do corpo docente e a existência da prática pedagógica dialógica guiada pela visão complexa do conhecimento e pela sua organização curricular conseqüente, prevista pela nova LDB (1996).

Espera-se que este artigo contribua para um melhor entendimento sobre a gestão descentralizada e democrática da educação superior, a construção coletiva do Projeto Político Pedagógico e sua estruturação curricular conseqüente, auxiliando deste modo, educadores e gestores universitários na gerência do conhecimento nas IES. Espera-se que haja, neste 
sentido, uma melhor eficiência do trabalho pedagógico em termos de currículo, métodos, conteúdos, avaliação e formas de organização dos ambientes de aprendizagem tendo em vista a melhoria da qualidade do ensino universitário, e, assim, dos sujeitos educativos que ali se encontram.

\section{A EDUCAÇÃO SUPERIOR E O PROCESSO DE GESTÃO DO CONHECIMENTO NA UNIVERSIDADE}

A função da universidade neste milênio é a de zelar pela qualidade do trabalho acadêmico que realiza e pela competência dos profissionais que forma. Deste modo, "o sentido essencial da responsabilidade social da educação de nível superior consiste em produzir e socializar conhecimentos que tenham não só mérito científico, mas também valor social e formativo" (DIAS SOBRINHO, 2005, p. 172). Isto indica que a instituição universitária tornou-se foco das atenções, pelo questionamento da qualidade do conhecimento nela produzido e dos processos educativos pelos quais é responsável, quais sejam, a disseminação do conhecimento científico e a formação de profissionais e cidadãos nas diferentes áreas.

Pensar a universidade sob este ângulo é entendê-la como uma instituição social e não como uma entidade administrativa. O conceito de universidade como instituição social, se contrapõe ao conceito de universidade Organizacional. A adoção desta visão requer um entendimento sobre a finalidade do ensino superior no contexto social global que determina e é determinado pela ação dos sujeitos que aí atuam, uma vez que a finalidade das instituições de educação é essencialmente de formação humana e por sua excelência é um "sistema de relações, com características interativas, que as diferenciam das empresas convencionais" (LIBÂNEO, 2001, p. 77).

A universidade como instituição social tem lida com a formação humana e o "exercício permanente da crítica, que se sustenta na pesquisa, no ensino e na extensão" (PIMENTA e ANASTASIOU, 2002, p. 162). Nesta condição a universidade:

\footnotetext{
Caracteriza-se como ação e prática social, pautando-se pela idéia de um conhecimento guiado por suas próprias necessidades e por sua própria lógica, tanto no que se refere à descoberta e invenção quanto à disseminação e produção do conhecimento. Desde suas origens, a universidade buscou efetivar os princípios de formação, criação, reflexão e crítica, tendo sua legitimidade derivada da autonomia do saber ante a religião e o Estado (PIMENTA e ANASTASIOU, 2002, p. 168).
}

Em decorrência destas características e finalidades da IES alguns princípios organizacionais e de funcionamento se impõe:

A convicção de que os espaços institucionais, democraticamente constituídos, por
expressarem e contemplarem a diversidade e a pluralidade de pensamento, são
espaços legítimos para efetivar essa finalidade; a convicção de que o processo
educativo de qualidade resulta da participação dos sujeitos nos processos
decisórios, o que se traduz no fortalecimento de práticas colegiadas e na condução
dos projetos e das ações educativas na universidade (PIMENTA E
ANASTASIOU, 2002, p. 163)

Estas idéias evidenciam que uma IES orientada por princípios democráticos e participativos, o processo de tomada de decisão se dá de forma coletiva, descentralizada e coletiva. Esta forma de agir acentua a importância de se perseguir objetivos comuns assumidos por todos. Em termos de proposta pedagógica do curso de graduação significa clareza sobre qual o papel social da educação superior? Sobre o perfil de egresso do curso? Ou seja, que homem se quer formar? Para viver em que sociedade? 
Estas questões são direcionadoras da organização da IES, pois todo sistema de educação orienta-se por uma concepção de homem e de mundo. Isto é, são os aspectos filosóficos que dão à educação seu sentido e seus fins. A filosofia, sendo a reflexão sistemática sobre o homem e sobre a concepção da vida, esta em estreita conexão com a Pedagogia, que é a reflexão sistemática sobre o ideal da educação e da formação humana (LIBÂNEO, 2001). Isto significa dizer que:

O caráter pedagógico da prática educacional se realiza por meio da ação consciente, intencional e planejada no processo de formação humana. São os objetivos (fins) e os meios estabelecidos por critérios socialmente determinados e que indicam o tipo de homem se quer formar, para qual sociedade, com que propósitos? Vincula-se, pois, a opções sociais e políticas referentes ao papel da educação num determinado sistema de relações sociais. A partir daí a Pedagogia pode dirigir e orientar a formulação de objetivos e meios do processo educativo (LIBÂNEO, 1994, p. 24)

Percebe-se que de modo geral, o pedagógico orienta-se pelo Político, que significa a construção de um Projeto de educação com base em: a) uma posição sobre a forma de gestão da IES (se democrática ou centralizada); b) um conceito de educação superior (sistema formador de profissionais para o mercado ou de profissionais-cidadãos e pesquisadores); c) critérios para a busca da qualidade da educação ( idênticos aos formulados pelas empresas: adaptabilidade e ajuste do mercado, competividade, rentabilidade, etc, ou aos de uma intuição social, que é o acesso ao conhecimento, à aprendizagens significativas, à autonomia e ao exercício da cidadania ativa).

Além do termo Político, cabe esclarecer o significado do termo Projeto e do termo Pedagógico no contexto da gestão universitária. O PPP não substitui a organização acadêmica, pois são coisas diferentes. "O Projeto é um guia para a ação, prevê, dá uma direção política e pedagógica para o trabalho escolar, formula metas, institui procedimentos e instrumentos de ação" (LIBÂNEO, 2001, p. 127). Pela gestão integrada põe-se em prática o processo organizacional para atender ao PPP, de modo que é este um instrumento da gestão.

Neste sentido, o termo Pedagógico é representativo de um modelo de educação que considera a pedagogia como a teorização sobre as práticas educacionais. Dessa teorização/reflexão resulta a formulação de objetivos e meios formativos para dar uma direção de sentido ao processo educativo. A ação pedagógica, portanto, não se refere apenas ao "como se faz", mas, principalmente ao por que se faz, orientando o trabalho educativo para as finalidades sociais e políticas almejadas pelo grupo de educadores. Assim, ter uma atitude pedagógica é dar uma direção de sentido (filosofia), um rumo, às práticas educacionais (LIBÂNEO, 2001).

Outros termos como educação, pedagogia e didática também merecem esclarecimentos, pois são termos bastante citados, entretanto, pouco explicados e discutidos nos trabalhos na área do ensino.

A educação atende a exigência social e individual na medida em que é através dela que as características especificamente humanas são desenvolvidas nos indivíduos. Conforme Talízina (1988, p.34):

O homem não nasce com formas de pensar pré-estabelecidas, com conhecimentos prontos sobre o mundo nem descobre novamente as leis do pensamento lógico nem as leis da natureza que a sociedade conhece: assimila tudo isso mediante a experiência acumulada pelas gerações anteriores. Subentende-se que, só depois de assimilar a experiência social e a ela recorrendo, o homem pode multiplicar essa experiência.

Isto equivale dizer que é na educação que o ser humano encontra os meios para assimilar a experiência da sociedade e multiplicá-la. Sem negar a importância dos aspectos anatômico-fisiológicos indispensáveis ao desenvolvimento do indivíduo - sem músculos, nervos e cérebro, não há ser humano, afinal —, o que se quer dizer é que o modo social de 
vida do ser humano, com suas leis e métodos específicos, é que determina o desenvolvimento humano.

A Pedagogia, como o estudo sistemático da educação, surgiu como campo de conhecimento, a partir da necessidade de pensar e sistematizar os estudos acerca do processo educacional. É uma ciência que estuda o processo educacional onde ele ocorre: na família, no trabalho, nos movimentos sociais, nos meios de comunicação e na escola/academia. Para a formação do professor essa ciência é fundamental porque historicamente, se preocupa em "identificar os elementos culturais que precisam ser assimilados pelos indivíduos da espécie humana para que eles se tornem humanos e, por outro lado, concomitantemente, estudar as formas mais adequadas de atingir esse objetivo" (SAVIANI, 2003, p.31).

Pode-se dizer que à pedagogia cabe a direção de sentido da educação (filosofia), e, à didática, como principal ramo de estudos da pedagogia, cabe a sistematização dos conteúdos do ensino e dos processos próprios para a construção do conhecimento no contexto educativo (quem ensinar? Por que ensinar? O que ensinar? Como ensinar? E como monitorar?). A didática:

\begin{abstract}
investiga os fundamentos, condições e modos de realização da instrução e do ensino. A ela cabe converter objetivos sócio-políticos e pedagógicos em objetivos de ensino, selecionar conteúdos e métodos em função desses objetivos, estabelecer os vínculos entre ensino e aprendizagem, tendo em vista o desenvolvimento e a aprendizagem dos alunos (LIBÂNEO, 1994, p. 26)
\end{abstract}

Este entendimento evidencia o objeto de estudo da Didática que é o processo ensinoaprendizagem, uma particularidade do processo educacional, em conseqüência, é um ramo da Pedagogia. Klingberg (1978, p. 35), ao falar sobre a relação da didática com a pedagogia, diz que:

A didática está estreitamente vinculada à teoria da educação [portanto, à Pedagogia]. Enquanto a didática analisa principalmente os processos (docentes e extradocentes) do ensino e da aprendizagem, o objeto da teoria educacional é o desenvolvimento de conceitos, conviç̧ões e modos de conduta do homem, a formação da personalidade em desenvolvimento.

Percebe-se assim, que a Didática apresenta-se como a teoria e a prática de ensino, pois, enquanto as metodologias das diferentes disciplinas se ocupam das questões pertinentes ao ensino em particular de uma determinada disciplina, a Didática se abstrai das particularidades das distintas disciplinas e generaliza as manifestações e leis essenciais do ensino e da aprendizagem nas diferentes disciplinas e nas formas de ensinar (KLINBERG, 1978).

Danilov e Skatkin (1978, p.21), corroboram com esta posição ao afirmar que a tarefa da didática, ao longo de seu desenvolvimento histórico, tem consistido em determinar o "conteúdo do ensino das novas gerações, em buscar os métodos mais eficientes para prover a sociedade de conhecimentos, habilidades e hábitos úteis e em revelar as leis objetivas ou regularidades desse processo". Para os autores, a didática, na estágio atual de seu desenvolvimento, tem como objeto a totalidade do processo de ensino, isto é: o conteúdo do ensino refletido nos planos e programas docentes e nos livros didáticos; os métodos e meios e recursos de ensino; as formas organizativas do ensino; o papel educativo do processo docente; as condições que propiciam o trabalho ativo do estudante e seu desenvolvimento intelectual.

Nessa perspectiva, a didática não se restringe ao que ocorre nas aulas nem à sua própria relação com os métodos, procedimentos e técnicas empregadas, mas envolve também a gestão, planificação e organização do processo de ensino-aprendizagem e sua relação 
com a educação, tendo em vista propiciar o desenvolvimento integral da personalidade dos estudantes (LIBÂNEO, 2001).

Isto indica que uma instituição social funciona e "realiza sua missão e objetivos, mediante tomada de decisões, direção e controle dessas decisões" (LIBÂNEO, 2001, p. 78). Este é o processo, que neste artigo, será tomado como referência para o termo gestão, ou mais especificamente, coordenação do curso de graduação.

Para que o ensino e a aprendizagem aconteçam em qualquer que seja o âmbito precisa haver planejamento e organização, do contrário haverá ingerência e ineficácia do processo educacional. Neste sentido, compreender o significado e a importância do Projeto Pedagógico de uma instituição de Ensino Superior, seu papel e sua relação com o currículo do curso é vital para qualquer professor-gestor.

Conforme o que foi discutido em parágrafos anteriores, toda proposta Pedagógica não acontece no espontaneísmo ela fundamenta-se, explicita ou implicitamente em alguns eixos principais. Entende-se como eixos vitais, uma concepção de homem e uma concepção de aprendizagem. Isto vem de encontro com o que pensa Libâneo (2001) o perfil de formação do egresso depende de objetivos mais amplos, é o resultado da visão e da relação que a IES estabelece com a sociedade. Ou seja, formar para que? Para a CONSERVAÇÃ̃O ou para a TRANSFORMAÇÃO social.

Isto significa dizer que existe uma relação direta entre a formação profissional e o mercado produtivo. À medida que o conhecimento torna-se o fator de produção, cabe às IES a função de formação e qualificação profissional, onde ações político-pedagógicas são implementadas no âmbito dos Pedagógicos institucionais e dos currículos dos cursos.

Entretanto, a tomada de posição no campo do currículo, depende de uma visão ciência e de conhecimento. Os paradigmas curriculares existentes e a organização curricular conseqüente, tem demonstrado que a educação graduada, mais especificamente a educação Contábil não garantido processos formativos de qualidade e uma formação acadêmica capaz de dar conta da complexidade e da modernidade.

Em relação aos cursos de Ciências Contábeis Marion (1996) aponta limitações e dificuldades dos alunos quanto à aprendizagem da Contabilidade Aplicada, em vista da excessiva concentração de disciplinas de natureza técnica, tornando a visão do profissional restrita à escrituração Contábil.

Iudícibus e Marion (1999) destacam as limitações e dificuldades dos alunos quanto à aprendizagem da Contabilidade Aplicada, em vista da excessiva concentração de disciplinas de natureza técnica, tornando a visão do profissional restrita à escrituração Contábil.

Em relação aos currículos estes autores assentam que o cenário educacional é delicado e apontam como principais fatores a falta de adequação curricular e atrelada à falta de um programa definido para a prática contábil esta a falta de preparo do corpo docente, deficiência na metodologia de ensino da Contabilidade introdutório e proliferação das instituições de ensino e órgão de classe.

Para Nossa (1999), a melhoria na qualidade de ensino depende, além de mudanças curriculares e estruturais das IES, da seriedade, dedicação e compromisso assumido pelos profissionais com vistas a formação profissional de qualidade e não apenas disponibilidade de informações sobre alguns conteúdos. Para ele, torna-se necessário a implementação do Currículo que forma o Contador Global, em que o conteúdo é trabalhado de forma interdisciplinar.

Os problemas educacionais atuais são decorrentes do modelo de ciência em voga na sociedade, o qual influência diretamente nas "questões epistemológicas e teorias de aprendizagem das quais derivam a mediação pedagógica e suas práticas correspondentes (disciplinar ou interdisciplinar) " (MORAES, 1996, p. 58). 

ainda é o de:

Em termos de educação superior, de acordo com Moraes, 1996, p. 58), o modelo

dividir o conhecimento em assuntos, especialidades, subespecialidades, centrada no professor e na transmissão do conteúdo que, em nome da transmissão do conhecimento, continua vendo o indivíduo como uma tabula rasa, produzindo seres subservientes, obedientes, castrados em sua capacidade criativa, destituídos de outras formas de expressão e solidariedade. E uma educação "domesticadora", "bancária", segundo Paulo Freire, que "deposita" no aluno informações, dados e fatos, onde o professor é quem detém o saber, a autoridade, que dirige o processo e um modelo a ser seguido.

Este ideário indica os pressupostos epistemológicos nos quais a educação superior se assenta. Neste sentido, Cunha (1998, p. 1) afirma que:

\begin{abstract}
A forte presença do paradigma da ciência moderna na sociedade ocidental acabou por cristalizar a forma tradicional de currículo, vendo-a como uma única possibilidade de organização. Esta, resume-se na lógica presente no nosso cotidiano acadêmico: dos fundamentos da ciência para sua aplicação; da teoria para prática; do básico para o profissionalizante.
\end{abstract}

Esta lógica de organização curricular que separa pensamento e ação é sustentada pela teoria de aprendizagem ambientalista/emprirista que parte do pressuposto de que primeiro o sujeito deve "adquirir" conhecimentos para depois poder aplicá-los na prática e em situações específicas. Nesta concepção:

A melhor forma de aprender é pela audição e registro das verdades científicas reconhecidas que, para serem adquiridas, precisam de exercícios de experimentação e memorização. Qualidade de um curso é medida pela extensão da carga horária das disciplinas e, portanto, quanto mais horas/aula o aluno cumpre, melhor é sua formação. A prática é entendida como comprovação da teoria, sendo que seu sucesso depende do grau de aproximação com o conhecimento já construído..

Estes fatos indicam e fortalecem o entendimento de que a organização e os processos de gestão na universidade, incluindo aí a direção, assumem diferentes signifícados conforme a concepção que se tem da educação superior e de seus objetivos em relação à sociedade e à formação dos alunos (MAZETTO, 2003).

Isto indica que à medida que estudos e pesquisas se voltam para o esclarecimento dos processos que envolvem o ensinar e aprender contribuem para a busca da qualidade dos processos educativos e melhoria da qualidade de vida dos que transitam neste nível de ensino. Nesta direção caminham as discussões a seguir. Serão explorados tópicos que envolvem as concepções de educação e de universidades, sua função social, bem como concepções sobre o projeto político pedagógico e a organização curricular que melhor pode concretizar as intenções nele assentadas. .

\title{
3 A GESTÃO DEMOCRÁTICA DA EDUCAÇÃO E SUAS IMPLICAÇÕES PARA A CONSTRUÇÃO DO PROJETO POLÍTICO PEDAGÓGICO
}

Os elementos para o enfrentamento dos desafios modernidade encontram-se na construção coletiva do Projeto Político Pedagógico Institucional (PDI), que poderá recuperar o papel da universidade como instituição social e questionar criticamente as funções que se espera que ela exerça. Esse projeto é pedagógico, por que discute o ensinar e o aprender num processo de formação, de construção da cidadania e não apenas de preparação técnica para uma ocupação temporal. 
Neste sentido, Mazetto (2003, p. 19-20) ressalta que a preocupação o ensino superior deve ter como finalidade a "formação do pesquisador, do cidadão e do profissional". Segundo este autor é preciso mudar o paradigma cientifico que orienta os currículos de graduação existentes e buscar a integração das diferentes áreas do saber, para que os alunos possam pesquisar com seus professores e produzir conhecimento sobre os problemas que emergem em suas comunidades. Assim poderão superar a formação voltada apenas para os aspectos cognitivos e desenvolver o pensamento científico e analítico, o senso crítico e a condições para construir seu próprio conhecimento.

A universidade social, desde sua criação, deve ter dentre suas preocupações a qualidade do fazer pedagógico. Esta preocupação evidencia-se pelo Planejamento Estratégico, quando é identificada a necessidade de a comunidade universitária (re) discutir, (re) definir e (re) elaborar o Projeto Pedagógico Institucional e o Projeto Pedagógico dos Cursos de Graduação (PIMENTA e ANASTASIOU, 2002). Neste sentido, a implementação, acompanhamento e avaliação dos projetos deve merecer especial atenção, tal como mencionado pelo Fórum de Pró-Reitores de Graduação das Universidades Brasileiras (2000, p. 23):

\footnotetext{
A dimensão de gerenciamento dos processos pedagógicos dos cursos é que irá garantir em boa medida ações interdisciplinares, atividades inovadoras no currículo e integração do pessoal docente para a consecução dos objetivos do curso.. [...] Desse modo, o processo de gestão dos cursos de graduação passa a ter importância fundamental, tanto na definição dos projetos pedagógicos dos cursos, quanto na constituição da concepção e forma de avaliá-lo e ainda no compromisso e integração dos docentes ao mesmo.
}

Estas idéias indicam que pela construção do projeto pedagógico do curso explicita -se e documenta-se as crenças, valores, significados, modos de agir premissas e intencionalidades, que guiara as ações e intenções da IES. Logo, fica expresso os parâmetros a partir dos quais se buscará a qualidade e pelos quais o projeto será avaliado. Portanto, para que o projeto pedagógico seja um instrumento de construção da qualidade, é preciso que ele seja sistemática e metodicamente utilizado pelo seu gestor principal - o Coordenador do Curso - como um instrumento de gestão.

Neste ponto Dias Sobrinho (2005, p. 172-173) ajudará a destacar um pouco mais sobre qual é o projeto de qualidade que se defende para a área Contábil neste início de século, quando diz que o sentido essencial da responsabilidade social universidade consiste em produzir e socializar conhecimentos que tenham não só mérito científico, mas também valor social e formativo".

Este pensamento indica que um projeto de qualidade tem como idéia a sociedade, a cidadania, o coletivo, a participação e a busca pela dignidade humana. Para Cunha $(2000$, p. 49) "as propostas curriculares construídas em torno de um projeto pedagógico exigem trabalho coletivo, diálogo, planejamento e interação entre os docentes, dentre outros aspectos".Esta idéia de coletivo, de participação e de construção e de descentralização do saber e do poder é que deve permear o processo de planejamento nas IES. O Projeto Político Pedagógico deve ser compreendido como instrumento e processo de organização da IES, conforme já destacado em tópicos anteriores. Neste caso, considera-se o já instituído tal como: Legislação, currículos, conteúdos, métodos, formas organizativas da IES, etc (LIBÂNEO, 2001). Neste ponto, a reflexão conjunta deve ser no sentido de entender melhor que tipo de educação se tem instuído e fomentado? No momento seguinte é hora de considerar o instituinte . Este momento será caracterizado pelo que o projeto institui, "estabelece, cria objetivos procedimentos, instrumentos, modos de agir, estruturas, hábitos, valores, ou seja, institui uma cultura educacional (...) neste sentido ele sintetiza os interesses, os desejos, as propostas dos educadores que trabalham na IES “( LIBÂNEO, 2001, p. 126). 
Um projeto de educação comum vai exigir que os educadores de cada instituição elejam um conjunto de intenções educativas e de diretrizes pedagógicas e que se articule para orientar a organização e o desenvolvimento da sua prática educativa. Referenciais mais amplos - de natureza político-filosófica, epistemológica e didático-pedagógica definidos conjuntamente, oferecerão as bases para a análise da realidade atual da universidade e o planejamento da intervenção sobre ela. Um projeto de educação deve responder a questões como tais como: Que tipo de sociedade se quer ajudar a construir? Que formação pretendese/deseja-se para os alunos sob a responsabilidade da instituição de educação? Que educação acredita-se ser capaz de contribuir para essa formação? A ausência de um projeto comum de educação nas IES tem-se evidenciado na forma de uma permanente tensão interna entre visões que se defrontam, muitas vezes, em falsas dicotomias, dificultando o diálogo entre os profissionais: a) formação humanista ou técnica? b) formar para a inclusão social e profissional ou para o mercado de trabalho? d) ensinar conteúdos ou desenvolver habilidades e competências? e) transmitir conteúdos ou possibilitar aprendizagens significativas e formação profissional?f) acumular conhecimento ou aprender a pensar, a questionar a realidade? g) avaliar para classificar ou para identificar necessidades e dificuldades a fim de adequar o processo ensino-aprendizagem?

Assim é que, para dar conta da tarefa educativa de forma coerente e integrada, é preciso que os profissionais das instituições de educação dialoguem entre si e busquem acordos fundamentais capazes de nortear suas ações educativas, quaisquer que sejam suas especialidades. Sem esses referenciais amplos, que funcionam como filtros comuns, a universidade fragmenta-se internamente, ficando sujeita a posicionamentos individuais desarticulados, a modismos e à pressão de demandas externas pontuais que encontram espaço na ausência de um projeto institucional consistente e coerente com a realidade.

\section{O PROJETO POLÍTICO PEDAGÓGICO DO CURSO DE CIÊNCIAS CONTÁBEIS E O CURRÍCULO GLOBALIZADO COMO INSTRUMENTO DE SUA CONCRETIZAÇÃO}

A superação dos currículos fechados e disciplinares que conduzem ao isolamento à competição e à individualização deve acontecer pela construção e desenvolvimento dos currículos integrados, que atribuem importância à prática, tanto no sentido de a prática ser a referência para a elaboração e desenvolvimento curricular como no sentido de entender a prática do currículo como um processo de investigação.

O movimento por um modelo de currículo integrado chegou ao Brasil por meio de autores espanhóis como Torres Santomé, 1998 ; Hernandez, 1998 entre outros. Tais estudos destacam a globalização das aprendizagens e a interdisciplinaridade. O termo globalização esta associado a característica da estrutura cognitiva e afetiva dos alunos que acentuam uma maneira própria de atribuir significado e construir e integrar conhecimentos. O termo interdisciplinaridade acentua a inter-relação entre conhecimentos, superando a separação e a falta de comunicação entre as disciplinas.

O papel da Matriz Curricular para os cursos de Ciências Contábeis na formação dos contadores é discutido por Riccio e Sakata, (2004) que apontam limites no que se refere aos currículos dos cursos e a observância e consideração de que as pesquisas se voltam para questões periféricas como sexo, raça, habilidades técnicas, bem como influências do meio educacional, social e político. Destacam que uma discussão que se torna importante nos dias de hoje é a internacionalização e a globalização de programas acadêmicos que podem envolver conhecimento de línguas estrangeiras, cultura geral, entre outros conhecimentos. Corroborando com este pensamento Araujo, et al. (2008, p.99) dizem que:

A Teoria da Contabilidade está sujeita à influência dos mais diversos elementos sociais, políticos e científicos e deve 'beber' em outras áreas de conhecimento na 
perspectiva de fundamentar teoricamente seus construtos, utilizando-se da transdisciplinaridade inerente às ciências sociais aplicadas.

Este entendimento sinaliza para um pensar integrado, globalizado, que precisa ser exercitado na formação profissional, por meio da matriz integrada e dos currículos abertos, preocupam-se com a integração das disciplinas, tem metas abertas e flexíveis na definição de competências e habilidades, os conteúdos podem ser organizados em áreas e temas geradores. A elaboração e o desenvolvimento da proposta conta com a participação dos professores, respeitando-os na sua autonomia, seus saberes experiências e profissionais ( PIMENTA e ANASTASIOU, 2002).

Dentre estas características de uma matriz curricular aberta esta a interdisciplinaridade. Falar de propostas integradoras (interdisciplinares) é um desafio. O movimento histórico que vem marcando a presença do enfoque interdisciplinar na Educação é um dos pressupostos diretamente relacionados a um contexto amplo e complexo de mudanças, pois abrange a área da educação e outros setores da vida social como a economia, a política e a tecnologia.

A necessidade da interdisciplinaridade na produção e na socialização do conhecimento escolar é estudada por vários autores (MORIN, 2001, 2005; SANTOS 2006) principalmente pelos que pesquisam as teorias curriculares e as epistemologias pedagógicas ( FAZENDA, 2002, JAPIASSU, 1976) . No geral, a literatura mostra ao menos uma posição consensual quanto ao sentido e à finalidade da interdisciplinaridade: ela busca responder à necessidade de superação da visão fragmentada nos processos de produção e socialização do conhecimento. É um movimento que caminha para novas formas de organização e socialização do conhecimento em todas as esferas sociais.

A educação precisa ser entendida e trabalhada de forma interdisciplinar, na qual o aluno seja um agente ativo, comprometido, responsável, apto a planejar suas ações, assumir responsabilidades, tomar decisões diante dos fatos e interagir no meio em que vive enfim, ser sujeito de sua aprendizagem. Cabe ao professor fazer esta ponte. Ao ser co-participante do processo o aluno aprende a planejar, a trabalhar com hipóteses e a encontrar soluções para os problemas postos pela realidade. Isto vem ao encontro com o que propõe (LUCK, 2001, p. 64), quando diz que:

\footnotetext{
A interdisciplinaridade é o processo de integração e engajamento de educadores, num trabalho conjunto, de interação das disciplinas do currículo escolar entre si e com a realidade, de modo a superar a fragmentação do ensino, objetivando a formação integral dos alunos, a fim de que exerçam a cidadania, mediante uma visão global de mundo e com capacidade para enfrentar os problemas complexos, amplos e globais da realidade.
}

Fazenda $(1979,1995,2002)$, percebe a interdisciplinaridade como articuladora do processo de ensino e de aprendizagem na medida em que se tornar atitude, Morin (2005) como um modo de pensar, Japiassu (1976) como pressuposto na organização curricular, como um fundamento para as opções metodológicas do ensinar, e, Gadotti (2006) como um elemento orientador na formação dos profissionais da educação.

É deste ponto de vista que se pretende tratar da construção do projeto pedagógico do curso de Ciências Contábeis e do currículo interdisciplinar como instrumento de sua concretização. A formação de contadores globalizados remete à discussão sobre a construção de uma proposta pedagógica para o curso de Ciências Contábeis e a elaboração de currículos adequados ao atual cenário econômico, em que a formação dos profissionais possa responder aos desafios que o mundo lhes coloca.

A organização curricular é entendida neste artigo como elemento fundamental que delineia as referências para a construção de práticas pedagógicas capazes de produzir significados e possibilitar a constituição de identidades sociais e culturais. Neste sentido, 
adota-se o conceito de currículo conforme Moreira e Candau (2007, p. 18), que o definem como "o conjunto de experiências escolares que se desdobram em torno do conhecimento, em meio a relações sociais, e que contribuem para a construção das identidades dos estudantes".

Esta definição evidencia a relação entre currículo, conhecimentos escolares sua socialização e contextualização a fim de que possam ser compreendidos, analisados, criticados e reconstruídos pelos alunos. È deste modo que serão sujeitos ativos, capazes de adquirir habilidades necessárias para estabelecer mudanças em seus espaços sociais. Por outro lado, isso implica considerar a importância da seleção dos conhecimentos que comporão a matriz currilar, pois é imprescindível que sejam significativos e relevantes para promover a mudança necessária e a ampliação do universo cultural do aluno

A LDB (1996) é uma tentativa de formar profissionais qualificados, ao propor a autonomia das IES estabelece diretrizes para o projeto pedagógico e busca a flexibilização curricular. O Parecer $\mathrm{N}^{\circ} \mathrm{CES} / \mathrm{CNE} 0146$ (2002) estabelece as Diretrizes Curriculares Nacionais para os cursos de graduação que devem: a) se constituir em orientações para a elaboração dos currículos; b) ser respeitadas por todas as IES; e, c) assegurar a flexibilidade e a qualidade da formação oferecida aos estudantes. Em relação a área Contábil indica que o curso deverá contemplar um perfil profissional que revele: "a responsabilidade social de seus egressos e sua atuação técnica e instrumental, articulada com outros ramos do saber e, portanto, com outros profissionais, evidenciando o domínio de habilidades e competências inter e multidisciplinares" (CES/CNE, 2002, p. 14). Para tanto as IES deverão estabelecer a organização curricular por meio de Projeto Pedagógico, com descrição dos seguintes eixos interligados de formação: I - Conteúdos de Formação Básica; II - Conteúdos de Formação Profissional; III - Conteúdos de Formação Teórico-Prática (CES/CNE, 2002, p. 15).

Nesta direção, Dagostim (2000) destaca que o contador atual, diferentemente daquele da década de 1945, que recebia os dados monetários, processava, extraia informações econômicas, financeiras e patrimoniais, deve ser um profissional preocupado com os resultados da empresa e com o sucesso do empreendimento. Para tanto deve ser participativo, ligado não somente ao desempenho econômico-financeiro, mas envolvido com o social, o ambiental e à administração da empresa tomando parte nas decisões.

Pesquisadores, professores e profissionais da área Contábil de um modo geral tem manifestado preocupação em relação à formação dos futuros Contadores, advertindo para a divergência que existe entre a formação acadêmica que recebem e o que o mercado de trabalho exige. Esta preocupação tem conduzido despertado o interesse de pesquisas de pesquisas e estudos que visam identificar as mudanças que vem sendo implementadas na área do currículo e voltam-se para a investigação da prática da interdisciplinaridade e flexibilização do currículo, buscam captar se estas modificações estão ocorrendo ou não, neste sentido, procuram conhecer a percepção dos professores, dos coordenadores e alunos sobre o assunto.

Padoan e Clemente (2006) realizaram um estudo junto aos docentes do curso de Contábeis e postulam que "a Contabilidade é sustentada por três teorias: mensuração, informação e decisão. [...]" Ao estudarem as disciplinas em vista da integração e articulação dos conhecimentos contábeis apontaram para a importância da Interdisciplinaridade na formação do Contador. $\mathrm{O}$ estudo evidenciou os seguintes pontos: prevalência do tecnicismo no ensino de Contabilidade e do conteudismo, quantidade de disciplinas em detrimento da qualidade do ensino destes conteúdos e, como conseqüência, visão pouco integradora das disciplinas. Os autores apontam para a necessidade de revisão da proposta pedagógica e para a superação da disciplinaridade, em prol de uma formação dos futuros profissionais, que lhes de condições de desempenhar com competência sua profissão. 
Estes resultados são reforçados pelo estudo de Passos (2004) que investigou a percepção de coordenadores dos cursos de Ciências Contábeis sobre pesquisa, planejamento pedagógico e matriz curricular. Os resultados revelaram a existência de um ensino técnico, centrado no mercado de trabalho e em matérias técnicas da área contábil, com baixo nível de relacionamento entre disciplinas.

Estes dados haviam sido reforçados no estudo de Paiva (1999, p. 93) quando informou que "a interdisciplinaridade dentro do próprio curso de Ciências Contábeis é praticamente inexistente". A razão é a de que as disciplinas / conteúdos são lecionados de forma isolada. Ele conclui que o aluno não consegue formar uma compreensão global e indivisível da Contabilidade como Ciência, por receber uma visão fragmentada de várias Contabilidades: gerencial, comercial, industrial, pública, bancária, sem integração entre as disciplinas.

Todavia, fatos significativos também já haviam sido revelados pelo estudo de Silva (2003) e que deveriam fazer parte dos estudos e reflexões na área do ensino da Contabilidade. Os resultados apontaram a falta de consenso entre os especialistas sobre a definição exata do termo interdisciplinaridade, seguida de uma aplicação rara e assistemática entre as disciplinas. Para o autor a aplicação da Interdisciplinaridade nas Ciências Contábeis não é contemplada na literatura na dimensão de sua importância.

Corroborando com estas idéias e posturas na educação Contábil, Sinatora et al. (2005), analisaram as condições de oferta e de ensino da disciplina de Sistemas de Informação Contábeis nos cursos de Ciências Contábeis na cidade de São Paulo e identificaram como pontos problemáticos merecedores de atenção: a falta de integração entre os docentes do curso, causada principalmente por seu comparecimento pontual nos dias e horários das aulas; falta de interdisciplinaridade, como uma conseqüência o isolamento dos professores do curso.

Em estudo recente de GOMES GOMES; GUIMARÃES, I. P.; RIBEIRO, A.C.R., et al. (2009) analisaram o Projeto Político Pedagógico dos Cursos de Ciências Contábeis das Universidades Públicas do Estado da Bahia, e, além de outros problemas apontam limitações em relação a matriz curricular destes cursos que evidencia desarticulação entre a academia e a sociedade, onde o conhecimento constante do currículo, parece não refletir a realidade e as necessidades dos formando e como conseqüência a dicotomia entre a teoria e a prática. Os autores sugerem como superação desta problemática ações das IES em prol desta integração pela construção coletiva do PPP e do currículo interdisciplinar como instrumento de sua concretização.

Entretanto, para que isto ocorra, o coordenador de curso tem um papel fundamental, fato que requer capacitação, além de outras condições, já que gerir um curso é gerir, sobretudo, o pedagógico, um projeto de aprendizagem (CANTÍDIO, 1986). A gestão pedagógica, embora possa valer-se de conhecimentos e ferramentas já desenvolvidas pela teoria da Administração, requer conhecimentos da área da educação, da aprendizagem e do ensino, pois é a gestão do conhecimento de processos de aprendizagem que estão em jogo neste âmbito.

Estudo como o de Boutinet, 1990 evidencia que embora os coordenadores evidenciem a importância do PPP e de seu papel na gestão do curso, ainda assim, pode-se dizer que ele é muito mais considerado como um documento burocrático- produto, do que um processo guia para as ações. Isto evidencia-se de diversos modos: na necessidade de maior participação dos colegiados de curso na discussão e elaboração do PPP; na necessidade de os coordenadores de curso incluírem como referência o PPP no planejamento de suas ações, assim como nas atividades cotidianas, bem como considerá-lo nos processos de acompanhamento e avaliação das ações.

Considera-se, neste sentido, a necessidade de que a gestão pedagógica do curso seja melhor trabalhada e que leve em conta seu principal instrumento - o projeto político pedagógico. De acordo com Ehrensperger e Mendes (2005, p. 5, o projeto pedagógico é "sub- 
utilizado" em seu potencial de gerar de mudanças nas práticas pedagógicas dos docentes e nas práticas de gestão dos coordenadores de curso:

O que se tem observado é que tanto coordenadores de curso quanto professores, em grande parte das vezes, "deixam" o projeto pedagógico de lado e seguem suas práticas tradicionais: o coordenador exercendo ações burocráticas e isoladas e não realizando efetivamente uma gestão pedagógica fundamentada no projeto e o professor repetindo suas práticas isoladas de ensino, ou tentando, também, de forma isolada, empreender ações inovadoras.

Estas idéias refletem o significado e potencial do PPP em termos de adequação da proposta de educação às necessidades e realidade dos alunos que freqüentam o ensino superior ao mesmo tempo em que expressa sua subutilização no contexto das IES. Cunha (2000, p. 49), referindo- se às dificuldades de atuação articulada e coletiva dos docentes registra que "as propostas curriculares construídas em torno de um projeto pedagógico exigem trabalho coletivo, diálogo, planejamento e interação entre os docentes, dentre outros aspectos". Isto implica dizer que o coordenador de curso responde pela viabilização, integração e articulação do trabalho pedagógico-didático em ligação direta com os professores e alunos em função da qualidade de ensino. Para que isto ocorra, o coordenador precisa realizar uma adequada gestão pedagógica, o que requer capacitação, além de outras condições, já que gerir um curso é gerir, sobretudo, o pedagógico. E a gestão pedagógica, embora possa valer-se de conhecimentos e ferramentas já desenvolvidas pela teoria da Administração, requer conhecimentos da área da educação, pois é a gestão de uma realidade que exige conhecimentos sobre o ensinar e o aprender.

Um projeto de educação alinhado às necessidades e aprendizagem dos alunos e dos professores exige conhecimentos, habilidades, saberes, crenças e atitudes tais como:

i) Coordenar e gerir estudos, discussões e ações para a partir do diagnóstico da realidade escolar construir o Projeto Político e pedagógico do curso

ii) Assegurar a unidade de ação pedagógica do curso por meio da gerência de atividades curriculares e de ensino, propondo orientações e ações de desenvolvimento dos planos de ensino, tendo em vista a aprendizagem significativas dos alunos;

iii) Prestar assistência didático-pedagógica direta aos professores, por meio de reuniões de trabalho, especialmente em relação a práticas de gestão e manejo de metodologias específicas e diferenciadas para a sala de aula; para apoiá-los nas dificuldades de aprendizagem dos alunos e para desenvolver a competência crítico-reflexiva do docente;

iv) Cuidar dos aspectos organizacionais do ensino por meio da supervisão das atividades pedagógicas e curriculares, organização, conservação e incentivo do uso novos recursos, equipamentos e materiais didáticos;

v) Assegurar, em conjunto com os professores, a criação e o desenvolvimento de um clima de trabalho cooperativo e solidário entre os membros da equipe e a identificação de soluções técnicas e organizacionais para a gestão das relações interpessoais, inclusive para a mediação de conflitos que envolvam professores, alunos e outros agentes acadêmicos;

vi) Propor e coordenar atividades de formação contínua e de desenvolvimento profissional dos professores, visando o aprimoramento profissional em conteúdos e metodologias, proporcionada pela oportunidade de troca experiências e cooperação entre os docentes;

vii) Acompanhar e avaliar, por meio de práticas colaborativas, o desenvolvimento do plano de curso e de ensino, a atuação do corpo docente, os critérios e as formas de avaliação da aprendizagem dos alunos;

viii) Organizar dados, documentação e registro referentes aos aspectos quantitativos do curso, entre eles documentos de estruturação e de desenvolvimento de ações pedagógicas; 
ix) Planejar, coordenar, gerir, acompanhar e avaliar as atividades didáticopedagógicas, tendo como instrumentos registros reflexivos desta atuação (ação-reflexãoação).

Estas funções decorrentes de uma prática de ensino colaborativa e interativa, tem o PPP como instrumento de gestão do curso e o currículo como espaço para a sua concretização, inscrevem-se num movimento de renovação e exigem do coordenador do curso uma postura sempre atenta ao que esta acontecendo além da visão estratégica para identificar os avanços do grupo, fortalecer as ações e fomentar inovações.

\section{CONCLUSÕES}

Este artigo tem como objetivo refletir sobre formas de gestão do conhecimento na universidade, procurando identificar e apontar os processos que orientam a construção coletiva do Projeto Político Pedagógico do curso de Ciências Contábeis tendo o currículo como seu instrumento de concretização. Verificou-se que a universidade como instituição social se diferencia de uma organização administrativa, pelo fato de que é orientada historicamente pela formação humana, pela reflexão de seus princípios, pela reflexão teórica e prática de sua filosofia da educação e pela avaliação crítica e constante de sua ação. Este entendimento de educação e de universidade é guiado por formulação teórica da qual decorre todo um sistema de valores que influencia não somente o processo de construção do conhecimento, mas também a maneira de ser, de fazer e de viver/conviver, fato que impõe um processo decisório coletivo, descentralizado e participativo.

A construção da autonomia e do saber fazer requer modelos de ensino flexíveis que permitam uma visão integrada do conhecimento e da realidade. A totalidade e o movimento é o ponto vital, os fenômenos não podem ser separados uns dos outros e, portanto, não existe a fragmentação do conhecimento, da realidade e do pensamento. Esta visão conduz à compreensão do mundo físico como uma rede de relações e não mais como uma entidade fragmentada. Este modelo epistemológico requer modelos de gestão guiados pela construção coletiva do PPP, onde o currículo interdisciplinar e a prática pedagógica dialógica são os instrumentos de sua concretização.

Isto vem ao encontro com das necessidades da ciência Contábil que precisa superar os limites impostos pelo paradigma dominante e por modelos epistemológicos que não contemplam o movimento, a complexidade e reproduzem uma visão simplista da essência da Contabilidade que não atende as reais necessidades da área que clama por sistemas abertos e complexos e em interação com a contemporaneidade. Deste modo, é preciso construir e explicitar o projeto Político pedagógico de cada curso é uma tarefa necessária à efetivação de um processo de formação profissional conseqüente. E a construção desse projeto não pode prescindir da percepção crítica da função social da Universidade e do compromisso político e ético do trabalho docente, nem da discussão epistemológica e da análise crítica dos paradigmas que orientam os processos de seleção, organização, construção e socialização dos conhecimentos nas várias situações do contexto universitário.

Conclui-se, assim, que a construção e gestão do Planejamento Educacional e de modo particular a sua aplicação, são de enorme importância, ao mesmo tempo que se apresenta como um grande desafio aos gestores das IES. Esta gestão é desafiante porque gerir de forma racional, sem se utilizar dos princípios da administração científica/taylorista-Fordista exige de todos os seus atores uma relação dialógica e o uso de técnicas e habilidades humanas eficazes e adequadas aos objetivos a que se propõe a Educação Superior.

Sabe-se que não cabe aos investigadores traçarem linhas normativas do que deverá ser a função do docente-coordenador ou a nova cultura profissional dos professores, mas sim seu esforço de compreensão das questões que envolvem os processos gerência no âmbito da educação e mais especificamente do ensinar e do aprender no âmbito da universidade. 
Entende-se que o desvelamento das teorias e crenças constituintes da gestão participativa que orienta a construção coletiva do PPP e do currículo globalizado e interdisciplinar como seu instrumento de concretização, poderá contribuir para o repensar da universidade como instituição social e, assim, anunciar e defender o projeto de qualidade da educação que atende as necessidades e realidades social neste novo século.

Espera-se que este estudo contribua para uma ampliação das discussões e estudos sobre a gestão universitária, mais especificamente a construção do PPP da área Contabilidade, e, faça assim, emergir caminhos que conduzam à inovações metodológicas e à implementação de políticas que atendam às reais necessidades dos alunos e possibilitem aprendizagens significativas no contexto universitário.

Como possibilidade de pesquisas futuras sugere-se investigar: a) quais são as crenças, atitudes e saberes do professor-coordenador do curso de Ciências Contábeis e que reflexos produzem na gestão do PPP e do currículo do curso? b) Como estão sendo vistas e tratadas questões referentes aos conceitos de flexibilidade e autonomia da universidade e que constituem o ideário da qualidade da educação implementado pela nova LDB (1996)? c)Quais são as dificuldades e desafios vivenciados pelos coordenadores dos cursos de Ciências Contábeis diante do atual processo de convergência, no Brasil, com as Normas Internacionais de Contabilidade o qual cobra novo perfil dos futuros profissionais e neste contexto, um novo perfil de educador, onde formação dos professores se configura como um elemento vital?

\section{REFERÊNCIAS}

ARAÚJO, Márcio Pires de, et al. Uma contribuição à avaliação do ativo intangível 36 anos depois: uma reflexão em torno do pensamento do professor Eliseu Martins. Revista de Educação e Pesquisa em Contabilidade. v. 2, n. 2, p. 95-100. maio/ago. 2008. Disponível em: http://www.repec.org.br/index.php/repec/article/viewPDFInterstitial/30/32>. Acesso em: 25-07-2009.

BRASIL. Lei n 9.394/96, de 20 de dezembro de 1996. Estabelece as diretrizes e bases da educação nacional. Disponível em:

$<$ http://portal.mec.gov.br/seed/arquivos/pdf/tvescola/leis/lein9394.pdf $>$. Acesso em 27/07/2009.

Conselho Nacional de Educação / Câmara de Educação Superior, CES/CNE.

Diretrizes Curriculares Nacionais dos cursos de graduação em Direito, Ciências Econômicas, Administração, Ciências Contábeis, Turismo, Hotelaria, Secretariado Executivo, Música, Dança, Teatro e Design. Brasília,DF:MEC, 2002.

BOUTINET, Jean-Pierre. Antropologia do projecto. Lisboa: Instituto Piaget, 1990.

CANTÍDIO, W. M. As Coordenações de Curso e os Departamentos na Administração Setorial Escolar. Coleção Documentos Universitários. UFC/Fortaleza,1981.

CERVO, A. BERVIAN, P. Metodologia Científica. 5 ed. São Paulo: Prentice Hall, 2002.

CHAVES, A. O ciclo de formação geral e a reforma do ensino superior. [2007].

Disponível em:

http://www.educacao.gov.br/reforma/Documentos/ARTIGOS/2005.3.7.17.4.56.pdf. Acesso em: 30 mar. 2007.

CHAUÍ, M. A universidade em ruínas. In.: TRINDADE, H.(Org.).Universidade em ruínas: na república dos professores, Petrópolis: Vozes/ Rio Grande do Sul: CIPEDES, 1999, p. 211. 
CUNHA. Maria Isabel da. Paradigmas científicos e propostas curriculares. Revista Interface - Comunic, Saúde, Educ. 2, 1998.

. O ensino como mediador da formação do professor universitário. In: MOROSINI, Marília Costa (Org.) Professor do ensino superior: identidade, docência e formação. Brasília: INEP: 2000. p. 45-51.

Ensino como mediação da formação do professor universitário. In:

MOROSINI, M. Org. Professor do ensino superior: identidade, docência e formação. Brasília: Plano, 2001, p. 79-92.

DAGOSTIM, Salézio. para o Reestruturando o Ensino da Contabilidade Século XXI. Brasília: CFC, 2000.

DANILOV, M; SKATKIN, M. N. Didáctica de la escuela media. Ciudad de La Habana: Editorial Pueblo y Educación, 1978.

DIAS SOBRINHO, José. Dilemas da Educação Superior no Mundo Globalizado: Sociedade do Conhecimento ou Economia do Conhecimento? São Paulo: Casa do Psicólogo, 2005.

EHRENSPERGER, R. M. G.; MENDES, G. M. L. O assistente pedagógico como suporte para a gestão pedagógica dos cursos de graduação: o caminho da Universidade do Sul de Santa Catarina. In: ENCONTRO DE DIRIGENTES DE GRADUAÇÃO DAS IES PARTICULARES, 4., 2005, Rio de Janeiro. Anais... Rio de Janeiro: Univ. Cândido Mendes, FUNADESP, 2005.

FAZENDA, I. C. A. Integração e interdisciplinaridade no ensino brasileiro: efetividade ou ideologia. São Paulo: Loyola, 1979.

ed. São Paulo: Papirus, 1995.

.FAZENDA, I. C. A. Interdisciplinaridade: história, teoria e pesquisa. $2^{\mathrm{a}}$.

Interdisciplinaridade: um projeto em parceria. 5a . ed. São Paulo: Loyola, 2002.

FÓRUM BRASILEIRO DE PRÓ-REITORES DE GRADUAÇÃO. Indicadores e qualidade da graduação. Campinas, 2000.

GADOTTI, Moacir. Interdisciplinaridade: atitude e método. São Paulo: In: Instituto Paulo Freire. Disponível: <www.paulofreire.org>. Acesso em: 26 dez. 2006.

GOMES, Sonia Maria da Silva, et al. Uma análise dos projetos político-pedagógicos dos cursos de Ciências Contábeis das Universidades Públicas do Estado da Bahia. Revista do Conselho Federal de Contabilidade, n. 178, julho/agosto de 2009.

HARGREAVES, Andy. O Ensino na sociedade do conhecimento - educação na era da insegurança. Trad. Roberto Cataldo Costa. Porto Alegre: Artemed, 2004.

HERNÁNDEZ, Fernando. Transgressão e mudança na educação: os projetos de trabalho. Porto Alegre: ArtMed, 1998.

IUDÍCIBUS, Sérgio; MARION, José C. Introdução à teoria da contabilidade para o nível de graduação. São Paulo: Atlas, 1999.

JAPIASSU, Hilton. Interdisciplinaridade e Patologia do Saber. Rio de janeiro: Imago Editora LTDA, 1976.

KLINGBERG, Lothar. Introducción a la didáctica general. Ciudade de la Habana: Editorial Pueblo y Educación, 1978. 
LIBANEO, J. C. Organização e Gestão da escola: teoria e prática. Goiânia: Alternativa, 2001.

LUCK, H. Pedagogia da interdisciplinaridade. Fundamentos teórico - metodológicos. Petrópolis: Vozes, 2001.

MARION, J. C. O ensino da contabilidade. São Paulo: Atlas, 1996.

MASETTO, Marcos Tarciso. Competência pedagógica do professor universitário. São Paulo: Summus, 2003.

MORAES, Maria Cândida. O paradigma educacional emergente: implicações na formação do professor e nas práticas pedagógicas. Em Aberto, Brasília, ano 16. n.70, abr.jun. 1996.

MOREIRA, A . F . B. ; CANDAU, V. M. Indagações sobre currículo: currículo, conhecimento e cultura. Brasília: Ministério da Educação, Secretaria de Educação Básica, 2007.

MORIN, Edgar. A cabeça bem-feita: repensar a reforma, reformar o pensamento. Rio de Janeiro: Bertrand Brasil, 2001.

Educação e complexidade, os sete saberes e outros ensaios. São Paulo: Cortez, 2005.

NOSSA, V. Ensino da contabilidade no Brasil: uma análise crítica da formação do corpo docente. Dissertação (Mestrado em Ciências Contábeis) - Faculdade de Economia, Administração e Contabilidade da Universidade de São Paulo, FEA/USP. São Paulo, 1999.

PAIVA, S. B. O ensino da Contabilidade: em busca da interdisciplinaridade. Revista Brasileira de Contabilidade, Brasília, v. 28, n. 120, p. 89-93, 1999.

PADOAN, F. A. C., CLEMENTE, A. A interdisciplinaridade no ensino da Contabilidade: um estudo empírico da percepção dos docentes. CONGRESSO USP DE

CONTROLADORIA E CONTABILIDADE, 6., 2006, São Paulo. Anais eletrônicos...

Disponível em http://www.congressoeac.locaweb.com.br/artigos62006/551.pdf. Acesso em 10/01/2007.

PASSOS, I. C. A interdisciplinaridade no ensino e na pesquisa contábil: um estudo no município de São Paulo, 2004. Dissertação (Mestrado em Controladoria e Contabilidade) Faculdade de Economia, Administração e Contabilidade, Universidade de São Paulo, São Paulo, 2004.

PIMENTA, S. G. \& ANASTASIOU, L. G. C. Docência no ensino superior. São Paulo: Cortez, 2002 (Coleção Docência em formação).

PINHEIRO, E. J. Sistema didático interdisciplinar para o curso de ciências contábeis. FÓRUM NACIONAL DE PROFESSORES DE CONTABILIDADE, 4., 2003, Gramado, RS.

ROZA, J. P. A pesquisa no processo de formação de professores: intenções e experiências docentes e discentes e as limitações deste exercício - um olhar sob duas realidades educacionais. Dissertação (Mestrado em Educação) - Programa de Pós Graduação em Educação, Universidade Federal do Rio Grande do Sul, Porto Alegre, 2005.

RICCIO, Edson L; SAKATA, Marici C. G. Evidências da Globalização na Educação Contábil: estudo das grades curriculares dos cursos de graduação em universidades brasileiras e portuguesas. Revista Contabilidade e Finanças - USP. São Paulo: FEA/USP, n. 35, p. 35 - 44, mai./ago. 2004.

SANTOS, B. S. Um discurso sobre as ciências. Lisboa: Afrontamento, 1987. 
. A gramática do tempo: para uma nova cultura política. São Paulo:

Cortez, 2006.

SANTOMÉ, Jurjo Torres. Globalização e interdisciplinaridade. São Paulo: Artes Médicas, 1998.

SAVIANI, D. Saber escolar, currículo e didática. 3.ed.Campinas: Autores Associados, 2000.

SAVIANI, Dermeval. Pedagogia Histórico-crítica: primeiras aproximações. 8 ed. São Paulo: Cortez; Autores Associados, 2003. (Coleção polêmicas do nosso tempo; v. 40).

SAVIANI, Demerval. Histórias das idéias pedagógicas no Brasil. Campinas: Autores Associados, 2007.

SINATORA, J. R. P., PELEIAS, I. R., SILVA, D. da. FARIA, A. C. de. Construção e validação de uma escala de atitude para a avaliação do ensino de Sistemas de Informação nos cursos de Ciências Contábeis da cidade de São Paulo. ENCONTRO NACIONAL DOS PROGRAMAS DE PÓS-GRADUAÇÃO EM ADMINISTRAÇÃOENANPAD, 29., Brasília, DF. Anais... Rio de Janeiro: ANPAD, 2005. 1 CD-ROM.

TALÍZINA, N. F. Psicologia de la enseñanza. Moscou: Editorial Progresso, 1988. 